
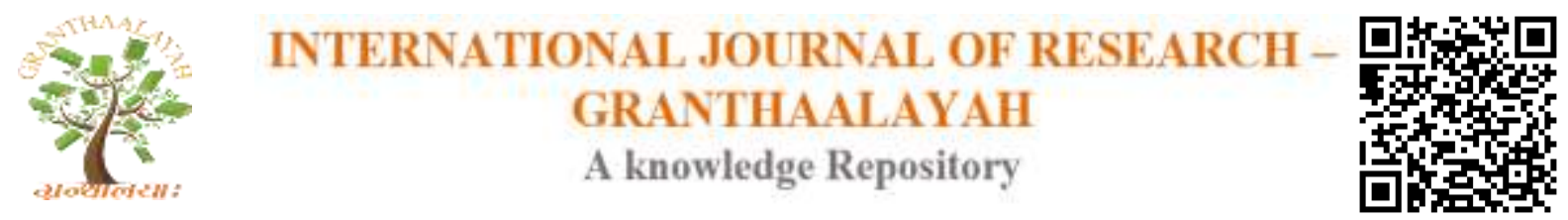

Science

\title{
FACTORS ASSOCIATED WITH PRELACTEAL FEEDING IN AFAR REGIONAL STATE, NORTHEASTERN ETHIOPIA: A CROSS SECTIONAL STUDY
}

Misgan Legesse Liben ${ }^{* 1}$, Abel Gebre Wuneh ${ }^{1}$, Nejimu Biza Zepro ${ }^{2}$, Afework Mulugeta ${ }^{3}$

${ }^{1}$ Department of Public Health, College of Medical and Health Sciences, Samara University, Afar, Ethiopia

${ }^{2}$ Department of Nursing, College of Medical and Health Sciences, Samara University, Afar, Ethiopia

${ }^{3}$ School of Public Health, College of Health Sciences, Mekelle University, Mekelle, Ethiopia

\begin{abstract}
Introduction: Proper infant and young child feeding is critical for child health and survival. Despite of this fact, prelacteal feeding is still common in different parts of the world. Therefore, this study was conducted to assess prelacteal feeding practices and associated factors among mothers of children aged 6-23 months in Afar Regional State of Ethiopia.

Methods: A community based cross sectional study was conducted in 2016 in Afar Regional State. A multistage cluster sampling was employed to select mothers of children aged 6-23 months. Data were cleaned, coded and entered into EpiData version 3.02. Then, data were exported to SPSS version 20 statistical package for analysis.

Results: About $96 \%$ of the study children had ever breastfed. Of the mothers who had ever breastfed their index child, 42.9\% [95\% CI: 39.0\%, 47\%] reported giving prelacteal feeds to their children. The most common prelacteal foods were raw butter (54.2\%) and animal milk (28.5\%). Being housewife, women of husbands without formal education, initiating breastfeeding after one hour of birth, having increased household income and lack of awareness on proper breastfeeding practices were associated with increased odds of prelacteal feeding practices.

Conclusion: This study showed that nearly four women in every ten practiced prelacteal feeding. Therefore, health education and information programs on the advantages of early initiation of breastfeeding and the disadvantages prelacteal feeding at the village level for housewives, and strengthening health extension package could be important to hamper prelacteal feeding practices.
\end{abstract}

Keywords: Prelacteal; Children Aged 6-23 Months; Afar; Ethiopia.

Cite This Article: Misgan Legesse Liben, Abel Gebre Wuneh, Nejimu Biza Zepro, and Afework Mulugeta. (2017). "FACTORS ASSOCIATED WITH PRELACTEAL FEEDING IN AFAR REGIONAL STATE, NORTHEASTERN ETHIOPIA: A CROSS SECTIONAL STUDY." International Journal of Research - Granthaalayah, 5(7), 116-127. https://doi.org/10.29121/granthaalayah.v5.i7.2017.2112. 


\section{Introduction}

Breast milk is the ideal food for the healthy growth and development of infants and young children and it protects them from infection and its consequences. Hence, the United Nations Children's Emergency Fund (UNICEF) and World Health Organization (WHO) recommend exclusive breastfeeding for infants in the first 6 months [1-4]. This can prevent the introduction of microorganisms through contaminated foods or fluids. Studies revealed that exclusive breastfeeding for the first six month is associated with decreased probability of diarrhea mortality and morbidity [5-7]. In addition, it is associated with reduced acute respiratory infections [5,7]. Therefore, proper infant and young child feeding is critical for child health and survival.

Prelacteal foods are any fluid or food given before breastfeeding initiation $[2,5,8]$. This might include herbal drinks, banana [2], water, honey, milk other than breast milk [2, 7, 8], raw butter [8-10], ,] and sugar solution [8, 10-12].

Prelacteal feeding is discouraged because it exposes infants to pathogens and increases their risk of infection and allergy to the infant [2]. It is associated with child under nutrition [13, 14]. In addition, prelacteal feeding interferes with suckling and reduces breast milk production; make breastfeeding more difficult to establish [1,2]. Women who did not practice prelacteal feeding were more likely to breastfeed their child exclusively as compared to those who introduced prelacteal feeding [15-18].

Despite of this fact, prelacteal feeding is still common in different parts of the world. In Zambia 8.9\% of children received prelacteal feeding [19]. Furthermore, 19\% in Bangladesh [12], 34.5\% in India [20], 26.5\% in Nepal [21] and in Vietnam 73.3\% of children [22] fed on prelacteal feeds. In Ethiopia, about 27\% of infants received prelacteal foods [1]. About $9 \%$ of children in Arba Minch Zuria [23], North Wello zone (11.1\%) [24], Azezo district (21.1\%) [15], Mizan Aman town (22.6\%) [25], Debre Berhan Town (24.3\%) [26], Dabat district (26.8\%) [9], Bahir Dar city (27\%) [27] and 38.8\% of children in Raya Kobo district [8] fed on prelacteal foods. In Afar Regional state about 30\% of children received prelacteal feeds [1]. Furthermore, the prevalence of prelacteal feeding in Afambo district and Dubti town of Afar was 49.6\% [28] and 16.8\% [29], respectively.

Prelacteal feeding is one of the key components to assess optimal breastfeeding practices [30]. Hence, this study was conducted to assess prelacteal feeding practices and associated factors among mothers of children aged 6-23 months in Afar Regional State of Ethiopia. The findings of this study will be vital for health service providers and program managers to design intervention strategies that will reduce prelacteal feeding practices in Afar Regional state.

\section{Methods}

\subsection{Study Area and Period}

Afar National Regional state is one of the nine regions in Ethiopia. Administratively, the region is divided into five zones, which are further subdivided into 32 districts and 404 kebeles (the 
lowest administrative units next to district in Ethiopia). Currently, there are 6 hospitals, 62 health centers and 314 health posts in the region. This study was conducted during February 21 to March 09/2016 in zone one (Chifra district) and zone four (Ewa, Awra and Gulina districts) of Afar Regional State.

\subsection{Study Design, Sampling Procedure and Study Participants}

This is a secondary analysis of cross-sectional data. A community based cross sectional study was conducted in Afar Regional State. A multistage cluster sampling was employed to select mothers of children aged 6-23 months. First, among the five zones of Afar region, two zones (Zone one and Zone four) were purposively selected. Secondly, four districts were selected. Then, the sample size was proportionally allocated to the selected districts based on the size of the study targets. Thirdly, a kebele was defined as a cluster and a total of 13 clusters (5 from Chifra, 3 from Ewa, 2 from Awra and 3 kebeles from Gulina district) were randomly selected.

In the center of the selected kebeles (clusters) a spin of pencil was made to determine the direction in the selection of the first study subject. Then, the first household in the direction of the tip of the pencil was selected and the continued to the nearest adjacent households until the sample size was achieved. However, in situations where there was no enough number of study subjects the nearest cluster was included. If more than one eligible woman was found in a household, one was selected by lottery. Women who were unable to communicate were excluded from the study.

\subsection{Data Collection Process and Instrument}

Seven data collectors having diploma in health were recruited from each survey districts. The data collectors were selected based on their ability in the local language (Afar'af) and experience of at least two surveys over the last two years. The supervisors were three health professional having BSc degree in health. The authors trained the data collectors and supervisors for two days on the study instrument, consent form, how to interview and data collection procedure.

Data were collected using a pre-tested, structured and interviewer administered questionnaire adapted from Ethiopian Demographic and Health Survey [1], national nutrition survey questionnaire [31] and WHO [32]. The questionnaire was prepared first in English then translated in to Afar'af and back to English to check for consistency. Then, the questionnaire was pretested on one kebele in Gulina district which was not included in the study. The pretest was done to ensure clarity, wordings, logical sequence and skip patterns of the questions. The pretest amendments on the questionnaire were made accordingly. Finally, the Afar'af version of the questionnaire was used to collect the data.

\subsection{Study Variables}

The dependent variable was prelacteal feeding practice. Prelacteal feeding was defined as eating and/or drinking something other than breast milk before the initiation of breastfeeding [8]. It was assessed by asking mothers "Before initiation of breastfeeding, was the child given anything to drink and/or eat other than breast milk?". The independent variables were maternal 
characteristics (age, marital status, occupation, educational status, religion), paternal characteristics (occupation, educational status), household characteristics (household income, household head), child's sex, child feeding characteristics (early initiation of breastfeeding, advantages of exclusive breastfeeding and awareness on proper breastfeeding ractices). Early initiation of breastfeeding is the initiation of breastfeeding within hour after birth [32].

\subsection{Data Processing and Analysis}

The data were checked for completeness and consistencies. Data were also cleaned, coded and entered into EpiData version 3.02. Then, data were exported to SPSS version 20 statistical package for analysis.

The crude odds ratios (COR) with $95 \%$ confidence interval were estimated in the binary logistic regression analysis to assess the association between each independent variable and the outcome variable. Variables with p-value $<0.25$ in the binary logistic regression analysis were considered in the multivariable logistic regression analysis.

The Hosmer-Lemeshow goodness-of-fit with enter procedure was used to test for model fitness. Adjusted Odds Ratio (AOR) with 95\% confidence interval was estimated to assess the strength of the association, and a p-value $<0.05$ was used to declare the statistical significance in the multivariable logistic regression analysis. Variables with $\mathrm{p}$-value $<0.05$ in the multivariable analysis were considered as significant and independent predictors of prelacteal feeding practices among the study participants.

\subsection{Ethical Consideration}

A survey which produced these data received an ethical approval from Health Research Ethics Review Committee (HRERC) of Mekelle University dated 31 Dec 2015, and numbered ERC/0688/2015. An official letter was written from Samara University to the selected district administration offices. Then, support letter was written to the selected kebeles/clusters. Women enrolled in the study were informed about the study objectives, expected outcomes, benefits, the risks associated with it, the right to withdraw from the study at any time and not to answer any question they do not want to answer. Finally, a verbal consent was taken from the participants before the interview. Confidentiality of responses was maintained throughout the study.

\section{Results}

\subsection{Socio _ Demographic Characteristics of the Study Participants}

A total of 615 mothers of children aged 6-23 months were included. About $94 \%$ of the study mothers were housewives and only $4.1 \%$ were household heads. In addition, 545(88.6\%) of the study mothers and 537(87.3\%) of fathers of the index child did not attend formal education. Majority of the study mothers were between 20 and 34 years old (Table 1). 
Table 1: Socio _ demographic characteristics of the study participants in Afar Regional state, Northeastern Ethiopia, 2016

\begin{tabular}{|c|c|c|}
\hline Variables & Frequency & Percent \\
\hline $\begin{array}{l}\text { Maternal occupation } \\
\text { Housewife } \\
\text { Daily laborer } \\
\text { Government employee } \\
\text { Private business }\end{array}$ & $\begin{array}{l}580 \\
21 \\
10 \\
4\end{array}$ & $\begin{array}{l}94.3 \\
3.4 \\
1.6 \\
0.7\end{array}$ \\
\hline $\begin{array}{l}\text { Maternal educational status } \\
\text { Non formal education } \\
\text { Formal education } \\
\end{array}$ & $\begin{array}{l}545 \\
70 \\
\end{array}$ & $\begin{array}{l}88.6 \\
11.4 \\
\end{array}$ \\
\hline $\begin{array}{l}\text { Household head } \\
\text { Father of the index child } \\
\text { Mother of the index child }\end{array}$ & $\begin{array}{l}590 \\
25 \\
\end{array}$ & $\begin{array}{l}95.9 \\
4.1 \\
\end{array}$ \\
\hline $\begin{array}{l}\text { Marital status } \\
\text { Living together } \\
\text { Not living together }{ }^{\mu}\end{array}$ & $\begin{array}{l}602 \\
13\end{array}$ & $\begin{array}{l}97.9 \\
2.1\end{array}$ \\
\hline $\begin{array}{l}\text { Religion } \\
\text { Muslim } \\
\text { Orthodox }\end{array}$ & $\begin{array}{l}611 \\
4\end{array}$ & $\begin{array}{l}99.3 \\
0.3\end{array}$ \\
\hline $\begin{array}{l}\text { Paternal educational status } \\
\text { Non formal education } \\
\text { Formal education }\end{array}$ & $\begin{array}{l}537 \\
78\end{array}$ & $\begin{array}{l}87.3 \\
12.7\end{array}$ \\
\hline $\begin{array}{l}\text { Paternal occupation } \\
\text { Pastoralist } \\
\text { Government employee } \\
\text { Private business }\end{array}$ & $\begin{array}{l}527 \\
46 \\
42 \\
\end{array}$ & $\begin{array}{l}85.7 \\
7.5 \\
6.8 \\
\end{array}$ \\
\hline $\begin{array}{l}\text { Average monthly income } \\
\leq 500 \\
501-1000 \\
>1000\end{array}$ & $\begin{array}{l}428 \\
162 \\
25 \\
\end{array}$ & $\begin{array}{l}69.6 \\
26.3 \\
4.1 \\
\end{array}$ \\
\hline $\begin{array}{l}\text { Sex of index child } \\
\text { Male } \\
\text { Female }\end{array}$ & $\begin{array}{l}297 \\
318\end{array}$ & $\begin{array}{l}48.3 \\
51.7\end{array}$ \\
\hline $\begin{array}{l}\text { Age of child (month) } \\
6-11 \\
12-17 \\
18-23\end{array}$ & $\begin{array}{l}286 \\
147 \\
182 \\
\end{array}$ & $\begin{array}{l}46.5 \\
23.9 \\
29.6 \\
\end{array}$ \\
\hline Mean ( \pm SD) of child's age & \multicolumn{2}{|c|}{$13.4( \pm 5.54)$ months } \\
\hline $\begin{array}{l}\text { Maternal age (year) } \\
<20 \\
20-34 \\
>34\end{array}$ & $\begin{array}{l}43 \\
469 \\
103\end{array}$ & $\begin{array}{l}7.0 \\
76.3 \\
16.7 \\
\end{array}$ \\
\hline Mean $( \pm$ SD) of maternal age & \multicolumn{2}{|c|}{$27.8( \pm 6.43)$ years } \\
\hline
\end{tabular}

${ }^{\mu}$ Single, divorced, widowed.

\subsection{Child Feeding Practices}

Five hundred ninety (95.9\%) of the study children had ever breastfed, and $92(15 \%)$ reported that exclusive breastfeeding can prevent pregnancy. Of the 590 mothers who had ever breastfed 
their index child, 253 (42.9\%; $95 \%$ CI: 39.0\%, 47\%) reported giving prelacteal feeds to their children. The most common prelacteal foods were raw butter (54.2\%) and animal milk (28.5\%). One hundred eighty one (29.4\%) had ever heard about proper breastfeeding practices (Table 2).

Table 2: Child feeding practices among mothers of children aged 6-23 months in Afar Regional state, Northeastern Ethiopia, 2016

\begin{tabular}{|c|c|c|}
\hline 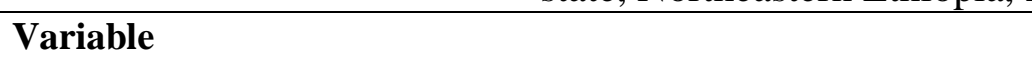 & Frequency & Percent \\
\hline $\begin{array}{l}\text { Ever breastfeeding } \\
\text { Yes } \\
\text { No }\end{array}$ & $\begin{array}{l}590 \\
25\end{array}$ & $\begin{array}{l}95.9 \\
4.1\end{array}$ \\
\hline $\begin{array}{l}\text { Early initiation of breastfeeding }(\mathbf{n}=\mathbf{5 9 0}) \\
\text { Yes } \\
\text { No }\end{array}$ & $\begin{array}{l}249 \\
341\end{array}$ & $\begin{array}{l}42.2 \\
57.8\end{array}$ \\
\hline $\begin{array}{l}\text { Prelacteal feeding }(\mathbf{n}=\mathbf{5 9 0}) \\
\text { Yes } \\
\text { No }\end{array}$ & $\begin{array}{l}253 \\
337 \\
\end{array}$ & $\begin{array}{l}42.9 \\
57.1 \\
\end{array}$ \\
\hline $\begin{array}{l}\text { Prelacteal feeds given }(\mathbf{n}=\mathbf{2 5 3}) \\
\text { Raw butter } \\
\text { Honey } \\
\text { Animal milk } \\
\text { Other }\end{array}$ & $\begin{array}{l}137 \\
36 \\
72 \\
8\end{array}$ & $\begin{array}{l}54.2 \\
14.2 \\
28.5 \\
3.1\end{array}$ \\
\hline $\begin{array}{l}\text { Breastfeeding is harmful for women } \\
\text { Yes } \\
\text { No } \\
\text { Do not know }\end{array}$ & $\begin{array}{l}191 \\
340 \\
84\end{array}$ & $\begin{array}{l}31.1 \\
55.3 \\
13.7\end{array}$ \\
\hline $\begin{array}{l}\text { Exclusive breastfeeding used as contraceptive } \\
\text { Yes } \\
\text { No }\end{array}$ & $\begin{array}{l}92 \\
523\end{array}$ & $\begin{array}{l}15.0 \\
85.0\end{array}$ \\
\hline $\begin{array}{l}\text { Ever heard about proper breastfeeding practices } \\
\text { Yes } \\
\text { No }\end{array}$ & $\begin{array}{l}181 \\
434 \\
\end{array}$ & $\begin{array}{l}29.4 \\
70.6\end{array}$ \\
\hline $\begin{array}{l}\text { Information source on proper breastfeeding practices } \\
(\mathrm{n}=181)^{*} \\
\text { Media } \\
\text { Health personnel } \\
\text { Health extension worker } \\
\text { Health development army } \\
\text { Clan leader } \\
\text { Religious leader }\end{array}$ & $\begin{array}{l}25 \\
72 \\
132 \\
65 \\
13 \\
18\end{array}$ & $\begin{array}{l}13.8 \\
39.8 \\
72.9 \\
35.9 \\
7.2 \\
9.9\end{array}$ \\
\hline
\end{tabular}

*Multiple answer.

\subsection{Factors Associated with Prelacteal Feeding}

Binary logistic regression analysis showed that paternal educational status, knowing exclusive breastfeeding as contraceptive, household headship, average monthly household income and awareness on proper breastfeeding practices were significantly associated with prelacteal feeding practice at $p<0.05$. In the multivariable logistic regression paternal educational status, maternal occupation, early initiation of breastfeeding, average monthly household income and awareness 
on proper breastfeeding practices remained as statistically significant factors significantly associated with prelacteal feeding practices at $\mathrm{p}<0.05$ (Table 3).

Women of husbands without formal education were about two times [AOR: 2.06; 95\% CI (1.17, 3.64)] more likely to practice prelacteal feeding as compared to women whose husbands attended formal education. Women who were housewives were more likely [AOR: 2.34; 95\% CI (1.02, 5.35)] to practice prelacteal feeding as compared to their counterparts. Compared to women with average monthly household income of 500 and less Ethiopian birr, women having 501 to 1000 Ethiopian birr were about two times [AOR: 1.98; 95\% CI $(1.32,2.97)$ ] more likely to fed prelacteal foods. Women who initiated breastfeeding lately were [AOR: 1.44; 95\% CI (1.01, 2.05)] more likely to practice prelacteal feeding compared to mothers who initiated breastfeeding early. Compared to women who had awareness on proper breastfeeding practices, women who lack of awareness on proper breastfeeding practices were more likely [AOR: 1.70; 95\% CI (1.16, 2.50)] to feed their child with prelacteal foods.

Table 3: Factors associated with prelacteal feeding practices in Afar Regional state, Northeastern Ethiopia, 2016

\begin{tabular}{|c|c|c|c|c|}
\hline \multirow[b]{2}{*}{ Variables } & \multicolumn{2}{|c|}{$\begin{array}{c}\text { Prelacteal } \\
\text { feeding }\end{array}$} & \multirow[b]{2}{*}{$\operatorname{COR}(95 \% \mathrm{CI})$} & \multirow[b]{2}{*}{$\operatorname{AOR}(95 \%$ CI $)$} \\
\hline & Yes & No & & \\
\hline $\begin{array}{l}\text { Paternal educational status } \\
\text { Non formal education } \\
\text { Formal education }\end{array}$ & $\begin{array}{l}230 \\
23\end{array}$ & $\begin{array}{l}286 \\
51\end{array}$ & $\begin{array}{l}1.78(1.06,3.01)^{*} \\
1\end{array}$ & $\begin{array}{l}2.06(1.17,3.64) * \\
1\end{array}$ \\
\hline $\begin{array}{l}\text { Maternal occupation } \\
\text { Housewife } \\
\text { Working outside home }^{\dagger}\end{array}$ & $\begin{array}{l}244 \\
9\end{array}$ & $\begin{array}{l}312 \\
25\end{array}$ & $\begin{array}{l}2.17(0.99,4.74) \\
1\end{array}$ & $\begin{array}{l}2.34(1.02,5.35) * \\
1\end{array}$ \\
\hline $\begin{array}{l}\text { Paternal occupation } \\
\text { Pastoralist } \\
\text { Other }^{\$}\end{array}$ & $\begin{array}{l}210 \\
43\end{array}$ & $\begin{array}{l}296 \\
41\end{array}$ & $\begin{array}{l}0.68(0.43,1.08) \\
1\end{array}$ & $\begin{array}{l}0.67(0.41,1.09) \\
1\end{array}$ \\
\hline $\begin{array}{l}\text { Sex of the child } \\
\text { Male } \\
\text { Female }\end{array}$ & $\begin{array}{l}117 \\
136\end{array}$ & $\begin{array}{l}172 \\
165\end{array}$ & $\begin{array}{l}0.83(0.59,1.14) \\
1\end{array}$ & $\begin{array}{l}0.76(0.54,1.07) \\
1\end{array}$ \\
\hline $\begin{array}{l}\text { Early initiation of breastfeeding } \\
\text { Yes } \\
\text { No } \\
\end{array}$ & $\begin{array}{l}96 \\
157 \\
\end{array}$ & $\begin{array}{l}153 \\
184 \\
\end{array}$ & $\begin{array}{l}1 \\
1.36(0.98,1.89)\end{array}$ & $\begin{array}{l}1 \\
1.44(1.01,2.05)^{*}\end{array}$ \\
\hline $\begin{array}{l}\text { EBF used as contraceptive } \\
\text { Yes } \\
\text { No }\end{array}$ & $\begin{array}{l}29 \\
224 \\
\end{array}$ & $\begin{array}{l}62 \\
275 \\
\end{array}$ & $\begin{array}{l}1 \\
1.74(1.08,2.80) *\end{array}$ & $\begin{array}{l}1 \\
1.61(0.97,2.65)\end{array}$ \\
\hline $\begin{array}{l}\text { Average monthly household income (ETB) } \\
\leq 500 \\
501-1000 \\
>1000\end{array}$ & $\begin{array}{l}163 \\
80 \\
10\end{array}$ & $\begin{array}{l}248 \\
75 \\
14\end{array}$ & $\begin{array}{l}1 \\
1.62(1.12,2.35)^{*} \\
1.09(0.47,2.51)\end{array}$ & $\begin{array}{l}1 \\
1.98(1.32,2.97)^{*} \\
1.44(0.60,3.45)\end{array}$ \\
\hline $\begin{array}{llll}\text { Awareness } & \text { on } & \text { proper } & \text { breastfeeding } \\
\text { practices } & & & \\
\text { Yes } & & & \\
\text { No } & & & \\
\end{array}$ & $\begin{array}{l}61 \\
192 \\
\end{array}$ & $\begin{array}{l}113 \\
224\end{array}$ & $\begin{array}{l}1 \\
1.59(1.10,2.29)^{*}\end{array}$ & $\begin{array}{l}1 \\
1.70(1.16,2.50)^{*}\end{array}$ \\
\hline $\begin{array}{l}\text { Household head } \\
\text { Father of index child } \\
\text { Mother }\end{array}$ & $\begin{array}{l}248 \\
5\end{array}$ & $\begin{array}{l}317 \\
20\end{array}$ & $\begin{array}{l}1 \\
0.32(0.12,0.86)^{*}\end{array}$ & $\begin{array}{l}1 \\
0.36(0.13,1.02)\end{array}$ \\
\hline
\end{tabular}


${ }^{\dagger}$ Daily laborer, government employee and private business. ${ }^{\$}$ Government employee and private business. $\mathrm{COR}=$ Crude odds ratio. $\mathrm{AOR}=$ Adjusted odds ratio. $\mathrm{CI}=$ confidence interval. EBF: Exclusive breastfeeding. ETB: Ethiopian birr. *significant at $\mathrm{p}<0.05$. Hosmer and Lemeshow Test $=0.866$.

\section{Discussion}

This study showed that breastfeeding is nearly universal in Afar Regional State where about $96 \%$ of the study mothers had ever breastfed. Of the study women who had ever breastfed their index child, $42.9 \%$ reported giving prelacteal feeds to their children. This was higher than the findings at Debre Berhan District (14.2\%) [10], Dubti town (16.8\%) [30], Debre Berhan Town (24.3\%) [26], Dabat district (26.8\%) [9] and Raya Kobo district (38.8\%) [8]. It was also higher than the findings from different parts of Ethiopia [24, 33-35] and India [20]. However, it was lower than the findings at Kersa (75.8\%) [36] and Afambo district (49.6\%) [29].This variation could be due to the difference in sociocultural characteristics across the study subjects.

The most common prelacteal food was raw butter (54.2\%). Similarity, raw butter was the most common prelacteal food in Dabat [9], Debre Berhan [10] and Raya Kobo districts. This was supported by qualitative finding in which women stated that raw butter is important to clean infants' stomach and to guide the infants' future behavior [8].

Women whose husbands did not attend formal education were about two times more likely to practice prelacteal feeding as compared to those whose husbands attended formal education. Likewise, women whose husbands did not attend any formal education had less knowledge about optimal breastfeeding practices in Arba Minch Zuria of Ethiopia. This could be explained in such a way that paternal education level is significantly associated with maternal knowledge of optimal breastfeeding practices [37].

Maternal occupational status was associated with prelacteal feeding practices. Compared to women who were working outside their home, housewives were more likely to practice prelacteal feeding. This finding is consistent with the study done in Bangladesh and Azezo district of northwest Ethiopia where unemployed women (housewives) were less likely to exclusively breastfed their child as compared to women who work outside their home $[12,15]$.

Compared to women with average monthly household income of 500 and less Ethiopian birr, women having 501 to 1000 Ethiopian birr were about two times more likely to fed prelacteal foods. In Raya Kobo district qualitative findings showed that women from rich families discard colostrum and feed their newborns with raw butter for the first 3 to7 days [38]. In addition, in Vietnam women in the middle and highest quartile were more likely to practice prelacteal feeding as compared to those in the lowest wealth quartile [7]. There were similar findings from Nepal [21] and India [39]. A relatively similar finding was also reported at Motta town of Ethiopia [18], Nigeria [40] and China [41]. However, a contrary finding was reported at Dabat district in which women in the lowest wealth status were associated with increased odds of prelacteal feeding as compared to those in the highest wealth status [9].

Women who initiated breastfeeding lately were more likely to practice prelacteal feeding compared to mothers who initiated breastfeeding early. Mothers who initiated breastfeeding after one hour of delivery were nearly three times more likely to practice prelacteal feeding compared 
to mothers who initiated breastfeeding within one hour of delivery [8]. Similar finding was reported at western Uganda [42]. This might be due to the fact that late initiation of breastfeeding provides more time for prelacteal feeding.

Compared to women who had awareness on proper breastfeeding practices, women who lack of awareness on proper breastfeeding practices were more likely to feed their child with prelacteal foods. Mothers who did not know the risks associated with prelacteal feeding were more likely to practice prelacteal feeding in Raya Kobo district [8]. In western Uganda mothers with poor level of information about breastfeeding were more likely to provide their child with prelacteal foods [42]. Likewise, in Dabat district women with poor and medium knowledge on infant and young child feeding (IYCF) were more likely to practice prelacteal feeding as compared to women with highest knowledge [9]. Relatively similar finding was reported from other parts of Ethiopia $[15,17,28,36]$.

The study could be subjected to the following limitations. First, since this was cross-sectional study, it is unable to establish causality between prelacteal feeding practices and the potential factors. Second, since the data were collected based on self-report of the mothers of children aged 6-23 months, it may be subjected to recall bias. Third, maternal and child health service utilization variables were not available for inclusion.

\section{Conclusion}

This study showed that about $43 \%$ of children received prelacteal feeding. This infant feeding malpractice was associated with paternal educational status, maternal occupation, early initiation of breastfeeding, average monthly household income and awareness on proper breastfeeding practices. Therefore, health education and information programs on the advantages of early initiation of breastfeeding and the disadvantages prelacteal feeding at the village level for housewives, and strengthening health extension package could be important to tackle prelacteal feeding practices.

\section{Abbreviations}

AOR: Adjusted odd ratio; CI: confidence interval; COR: Crude odds ratio; ERC: Ethical Review Committee; IYCF: infant and young child feeding; MI: Micronutrient initiative; UNICEF: United Nations Children's Fund; WHO: World Health Organization.

\section{Funding}

No specific fund was received for this analysis.

\section{Acknowledgments}

Authors thank MI-Ethiopia, data collectors, supervisors and study subjects. 


\section{Authors' Contributions}

All authors conceived, designed the primary study that produced these data. MLL, AGW and NBZ supervised the data collection. MLL conceptualized this problem, performed the data analysis, interpretation of data and drafted the manuscript. All authors had critically read, and had approved the final manuscript.

\section{Competing Interests}

The authors declare that they have no competing interests.

\section{References}

[1] Central Statistical Agency (CSA) Ethiopia: Demographic and Health Sur vey 2011.Addis Ababa: CSA and ORC Macro; 2011.

[2] WHO/UNICEF. Baby-friendly hospital initiative: revised, updated and expanded for integrated care. Geneva: World Health Organization; 2009. Available at http://www.who.int/nutrition/topics/bfhi/en/index.html

[3] FMOH-E (Federal Ministry of Health Ethiopia): National Strategy for Infant and Young Child Feeding Ethiopia. 2004. Available at http://www.motherchildnutritionorg/nutrition-protectionpromotion/pdf/mcn-nationalstrategy-for-infant-and-youngchild-feeding-pdf

[4] Greiner T. Exclusive breastfeeding: measurement and indicators. International Breastfeeding Journal. 2014; 9:18.

[5] Mihrshahi S, Oddy WH, Peat JK, Kabir I. Association between infant feeding patterns and diarrheal and respiratory illness: A cohort study in Chittagong, Bangladesh. International Breastfeeding Journal.2008; 3:28.

[6] Lamberti LM, Walker CF, Noiman A, Victora C, Black RE. Breastfeeding and the risk for diarrhea morbidity and mortality. BMC Public Health. 2011; 11(Supp 13 ):S15.

[7] Bandyopadhyay M. Impact of ritual pollution on lactation and breastfeeding practices in rural West Bengal, India. International Breastfeeding Journal. 2009; 4:2

[8] Legesse M, Demena M, Mesfin F, Haile D. Prelacteal feeding practices and associated factors among mothers of children aged less than 24 months in Raya Kobo district, North Eastern Ethiopia: a cross - sectional study. International Breastfeeding Journal. 2014; 9:189.

[9] Tariku A, Biks GA, Wassie MM, Gebeyehu A, Getie AT. Factors associated with prelacteal feeding in the rural population of northwest Ethiopia: a community cross-sectional study. International Breastfeeding Journal. 2016; 11:14.

[10] Asfaw MM, Argaw MD, Kefene ZK. Factors associated with exclusive breastfeeding practices in Debre Berhan District, Central Ethiopia: a cross sectional community based study. International Breastfeeding Journal. 2015;10:23.

[11] Aakre I, Lilleengen AM, Aarsand ML, A. Strand T, Barikmo I, Henjum S. Infant feeding practices in the Saharawi refugee camps Algeria, a cross-sectional study among children from birth to six months of age. International Breastfeeding Journal. 2017; 12:8.

[12] Joshi PC, Angdembe MR, Das SK, Ahmed S, Golam Faruque AS, Ahmed T. Prevalence of exclusive breastfeeding and associated factors among mothers in rural Bangladesh: a crosssectional study. International Breastfeeding Journal. 2014; $9: 7$.

[13] Teshome B, Kogi - Makau W, Getahun Z, Taye G. Magnitude and determinants of stunting in children under-five years of age in food surplus region of Ethiopia: The case of West Gojam Zone. Ethiop. J. Health Dev. 2009; 23(2):98-106. 
[14] Fentahun W, Wubshet M, Tariku A. Under nutrition and associated factors among children aged 6-59 months in East Belesa District, northwest Ethiopia: a community based cross-sectional study. BMC Public Health. 2016; 16:506.

[15] Asemahagn MA. Determinants of exclusive breastfeeding practices among mothers in azezo district, northwest Ethiopia. International Breastfeeding Journal. 2016; 11:22.

[16] Patil CL et al.: Early interruption of exclusive breastfeeding: results from the eight-country MALED study. Journal of Health, Population and Nutrition.2015; 34:10.

[17] Mekuria G, Edris M. Exclusive breastfeeding and associated factors among mothers in Debre Markos, Northwest Ethiopia: a cross-sectional study. International Breastfeeding Journal. 2015; 10:1.

[18] Tewabe T, Mandesh A, Gualu T, Alem G, Mekuria G, Zeleke H. Exclusive breastfeeding practice and associated factors among mothers in Motta town, East Gojjam zone, Amhara Regional State, Ethiopia, 2015: a cross-sectional study. International Breastfeeding Journal. 2017; 12:12.

[19] Katepa-Bwalya M, Mukonka V, Kankasa C, Masaninga F, Babaniyi O, Siziya S. Infants and young children feeding practices and nutritional status in two districts of Zambia. International Breastfeeding Journal. 2015.

[20] Sapna SP, Ameya AH, Rooma SP, Parmar A, Rashid K, Narayan A: Prevalence of exclusive breast feeding and its correlates in an urban slum in Western India. Int e-J Sci Med Educ. 2009; 3: 14-18.

[21] Khanal V, Adhikari M, Sauer K, Zhao Y. Factors associated with the introduction of prelacteal feeds in Nepal: findings from the Nepal Demographic and Health Survey 2011. International Breastfeeding Journal. 2013; 8:9.

[22] Nguyen PH, Keithly SC, Nguyen NT, Nguyen TT, Tran LM, Hajeebhoy N. Prelacteal feeding practices in Vietnam: challenges and associated factors. BMC Public Health. 2013; 13:932.

[23] Adugna DT. Women's perception and risk factors for delayed initiation of breastfeeding in Arba Minch Zuria, Southern Ethiopia. International Breastfeeding Journal. 2014; $9: 8$.

[24] Bililign N, Kumsa H, Mulugeta M, Sisay Y. Factors associated with prelacteal feeding in North Eastern Ethiopia: A community based cross-sectional study. International Breastfeeding Journal. 2016; 11:13.

[25] Tadele N, Habta F, Akmel D, Deges E. Knowledge, attitude and practice towards exclusive breastfeeding among lactating mothers in Mizan Aman town, Southwestern Ethiopia: descriptive cross-sectional study. International Breastfeeding Journal. 2016; 11:3

[26] Gultie T, Sebsibie G. Determinants of suboptimal breastfeeding practice in Debre Berhan town, Ethiopia: a cross sectional study. International Breastfeeding Journal. 2016; 11:5.

[27] Seid AM, Yesuf ME, Koy DN. Prevalence of Exclusive Breastfeeding Practices and associated factors among mothers in Bahir Dar city, Northwest Ethiopia: a community based cross-sectional study. International Breastfeeding Journal. 2013; 8:14.

[28] Liben ML, Abuhay T, Haile Y. Determinants of Child Malnutrition among Agro Pastorals in Northeastern Ethiopia: A cross sectional Study. Health Science Journal. 2016; 10(4):15.

[29] Liben ML, Gemechu YB, Adugnew M, Asrade A, Adamie B, Gebremedin E, Melak Y. Factors associated with exclusive breastfeeding practices among mothers in dubti town, afar regional state, northeast Ethiopia: a community based cross-sectional study. International Breastfeeding Journal. 2016; 11:4.

[30] Haile D, Biadgilign S. Higher breastfeeding performance index is associated with lower risk of illness in infants under six months in Ethiopia. International Breastfeeding Journal. 2015; 10:32.

[31] Ethiopian Health and Nutrition Institute (EHNR): Nutritional baseline survey report for the national nutrition program of Ethiopia. 2010. Available at www.ephi.gov.et/images/nutrition/nutrition\%20baseline\%20survey\%20reportpdf

[32] World Health Organization. Indicators for assessing infant and young child feeding practices: conclusions of a consensus meeting held 6-8 November 2007 in Washington D.C., USA. Geneva: World Health Organization; 2008. Available at 
http://www.unicef.org/nutritioncluster/files/IYCFE_WHO_Part1_eng.pdf

[33] Hailemariam TW, Adeba E, Sufa A. Predictors of early breastfeeding initiation among mothers of children under 24 months of age in rural part of West Ethiopia. BMC Public Health. 2015; 15:1076.

[34] Teka B, Assefa H, Haileslassie K. Prevalence and determinant factors of exclusive breastfeeding practices among mothers in Enderta woreda, Tigray, North Ethiopia:a cross-sectional study. International Breastfeeding Journal. 2015; 10:2.

[35] TadesseT, Mesfin F, Chane T. Prevalence and associated factors of non-exclusive breastfeeding of infants during the first six months in rural area of Sorro District, Southern Ethiopia: a crosssectional study. International Breastfeeding Journal. 2016;11:25

[36] Egata G, Berhane Y, Worku A: Predictors of non-exclusive breastfeeding at 6 months among rural mothers in east Ethiopia: a community-based analytical cross-sectional study. International Breastfeeding Journal. 2013; 8:8.

[37] Tamiru D, Mohammed S. Maternal Knowledge of Optimal Breastfeeding Practices and Associated Factors in Rural Communities of Arba Minch Zuria. International Journal of Nutrition and Food Sciences.2013; 2(3):122-129.

[38] Legesse M, Demena M, Mesfin F, Haile D. Factors Associated with Colostrum Avoidance among Mothers of Children Aged less than 24 Months in Raya Kobo district North-eastern Ethiopia: Community-based Cross-sectional Study. Journal of Tropical Pediatrics. 2015; 61:357-363.

[39] Raina SK, Mengi V, Gurdeep S. Determinants of Prelacteal Feeding Among Infants of RS Pura Block of Jammu and Kashmir, India. Journal of Family Medicine and Primary Care. 2012; $1(1): 27-9$.

[40] Onahet al.: Infant feeding practices and maternal socio- demographic factors that influence practice of exclusive breastfeeding among mothers in Nnewi South-East Nigeria: a crosssectional analytical study. International Breastfeeding Journal. 2014; 9:6.

[41] Gao H, Wang Q, Hormann E, Stuetz W, Stiller C, Biesalski HK, Scherbaum. Breastfeeding practices on postnatal wards in urban and rural areas of the Deyang region, Sichuan province of China. International Breastfeeding Journal. 2016; 11:11.

[42] Ogah AO, Ajayi AM SA, Okolo SN: A cross-sectional study of pre-lacteal feeding practice among women attending Kampala International University Teaching Hospital Maternal And Child Health Clinic, Bushenyi, Western Uganda. Asian Journal of Medical Sciences. 2012;4 (3):79- 85 .

*Corresponding author.

E-mail address: lmisgan @ yahoo.com 